\title{
Enhancement of 5-Fluorouracil Cytotoxicity by Pyridoxal 5'-Phosphate and Folinic Acid in Tandem
}

\author{
David Machover, Emma Goldschmidt, Rosella Mollicone, Farhad Haghighi-Rad, \\ Christophe Desterke, Yann Gaston-Mathé, Raphaël Saffroy, Claude Boucheix, \\ and Julien Dairou
}

Assistance Publique-Hôpitaux de Paris, Hospital Paul-Brousse, Villejuif, France (D.M., E.G., R.S.); INSERM U935, Villejuif, France (D.M., F.H.-R., C.D., C.B.); University Paris-Sud, Villejuif, France (D.M., R.M., F.H.-R., C.D., R.S., C.B.); University Paris-Saclay, Paris, France (D.M., R.M., F.H.-R., C.D., R.S., C.B.); INSERM U1193, Villejuif, France (R.S.); INSERM U1197, Villejuif, France (R.M.); YGM Consult SAS, Paris, France (Y.G.-M.); CNRS UMR 8601, Paris, France (J.D.); and University Paris-Descartes, Paris, France (J.D.)

Received March 26, 2018; accepted May 29, 2018

\section{ABSTRACT}

The current study originates from the assumption that, in tumors, levels of naturally occurring pyridoxal 5 '-phosphate (PLP) are too small to allow conversion of tetra hydro pteroylglutamate $\left(\mathrm{H}_{4} \mathrm{PteGlu}\right)$ into methylene tetra hydro pteroylglutamate $\left(\mathrm{CH}_{2}-\mathrm{H}_{4}\right.$ PteGlu $)$ in amounts required to improve inhibition of thymidylate synthase by 5-fluorouracil (FUra) through ternary complex stabilization. The hypothesis relates to the low affinity for cofactor of the PLPdependent serine hydroxymethyl transferase (SHMT), the enzyme that catalyzes formation of $\mathrm{CH}_{2}-\mathrm{H}_{4}$ PteGlu by transfer of the $\mathrm{C} \beta$ of serine to $\mathrm{H}_{4} \mathrm{PteGlu}$. Intracellular concentrations of PLP are smaller than the dissociation constant of SHMT for cofactor, which suggests that enzyme activity should be sensitive to PLP level changes. Three cancer cell lines were supplemented with PLP to investigate the influence of this cofactor on FUra cytotoxicity. Cells were exposed to FUra, FUra and folinic acid (FA), FUra and PLP, and FUra combined with both FA and PLP. The median-effect principle for concentration-effect analysis and combination indices were used to determine interactions on cytotoxicity. FUra cytotoxicity in vitro was enhanced by FA and PLP in tandem. Synergistic cytotoxic interaction of FUra with FA and PLP was demonstrated in HT29 and L1210 cells. Summation was found in HCT116 cells. Parenteral pyridoxamine was administered in mice to explore erythrocyte production of PLP in vivo. Cofactor attained levels in the range of the $K_{D}$ for binding to SHMT, and it was rapidly cleared from cells. Pharmacokinetics of pyridoxamine suggests that modulation of FUra by vitamin B6 could be achieved in vivo.

\section{Introduction}

Fluorodeoxyuridine monophosphate (FdUMP), the active metabolite of 5-fluorouracil (FUra), binds to thymidylate synthase (TS) and the cofactor N5-N10 methylene tetra hydro pteroylglutamate $\left(\mathrm{CH}_{2}-\mathrm{H}_{4} \mathrm{PteGlu}\right)$ to form a ternary complex (FdUMP-TS-CH ${ }_{2}-\mathrm{H}_{4} \mathrm{PteGlu}$ ) with concomitant inactivation of the TS (Santi et al., 1974; Danenberg and Danenberg, 1978; Lockshin and Danenberg, 1981). Stability of the complex increases as $\mathrm{CH}_{2}-\mathrm{H}_{4} \mathrm{PteGlu}$ level is augmented over a wide concentration range up to levels greater than $450 \mu \mathrm{M}$. Supplementation of cancer cell lines exposed to FUra or fluorodeoxyuridine with high concentration N5-formyl tetra hydro pteroylglutamate [5-HCO-H ${ }_{4}$ PteGlu; folinic acid (FA); leucovorin] in vitro results in greater formation of ternary complex

Authorizations: Murine experiments were performed under authorization DR2015-09 delivered by CEEE-55 from the Ethics Committee for animal experimentation at University Claude-Bernard Lyons 1.

This work was supported by the Institut du Cancer et d'Immunogénétique, Hospital Paul-Brousse (Villejuif, France).

https://doi.org/10.1124/jpet.118.249367. than with fluoropyrimidines as single agents, leading to potentiation of the cytotoxic effect (Ullman et al., 1978).

These findings led to the design of regimens of FUra combined with FA for patients with gastrointestinal carcinomas that possess greater antitumor efficacy than FUra as a single agent (Machover et al., 1982; Piedbois et al., 1992). Further changes in amounts of folates or use of the pure 6S-FA instead of the 6R,S mixture of enantiomers (Machover et al., 1992) did not convincingly improve antitumor effect.

Effectiveness of the biochemical modulation of the fluoropyrimidines by folates varies among cancer cells. Variation is thought to be due to differences in capacities for polyglutamation (Romanini et al., 1991) and for expansion of $\mathrm{CH}_{2^{-}}$ $\mathrm{H}_{4}$ PteGlu pools. From results of prior reports, it is unlikely that supplementation of cancer cells with any amount of folate would result in rise of $\mathrm{CH}_{2}-\mathrm{H}_{4} \mathrm{PteGlu}$ to concentrations required to increase the tightness of FdUMP binding to TS for maximum stability of the ternary complex. In most of these studies when cancer cells were exposed to folates in great amounts, only limited increase of $\mathrm{CH}_{2}-\mathrm{H}_{4}$ PteGlu concentration occurred, followed by rapid decline after discontinuation

ABBREVIATIONS: ANOVA, analysis of variance; $\mathrm{Cl}$, combination index; $\mathrm{F}_{\mathrm{a}}$, fraction of cells affected; FA, folinic acid; FdUMP, fluorodeoxyuridine monophosphate; FUra, 5-fluorouracil; $\mathrm{K}_{\mathrm{D}}$, dissociation constant; PL, pyridoxal; PLP, pyridoxal 5'-phosphate; PM, pyridoxamine; PN, pyridoxine; SHMT, serine hydroxymethyltransferase; TS, thymidylate synthase. 
of folate exposure (Wright et al., 1989; Houghton et al., 1990; Romanini et al., 1991; Zhang and Rustum, 1991; Boarman and Allegra, 1992; Priest et al., 1993; Voeller and Allegra, 1994; Machover et al., 2001).

One possible explanation for these findings is the rapid turnover of folates in cancer cells resulting from interconversion of folate cofactors (Nixon et al., 1973), including the irreversible reduction of $\mathrm{CH}_{2}-\mathrm{H}_{4}$ PteGlu to N5-methyl tetra hydro pteroylglutamate $\left(\mathrm{CH}_{3}-\mathrm{H}_{4}\right.$ PteGlu) (Fig. 1). Poor expansion of $\mathrm{CH}_{2}-\mathrm{H}_{4}$ PteGlu pools in cancer cells may also result from insufficient production of this folate. Synthesis of $\mathrm{CH}_{2}$ $\mathrm{H}_{4} \mathrm{PteGlu}$ from $\mathrm{H}_{4} \mathrm{PteGlu}$ results from two pathways. One is the transfer of $\mathrm{C} \beta$ of serine to $\mathrm{H}_{4} \mathrm{PteGlu}$ with formation of glycine and $\mathrm{CH}_{2}-\mathrm{H}_{4} \mathrm{PteGlu}$ catalyzed by serine hydroxymethyl transferase (SHMT), a ubiquitous pyridoxal 5'-phosphate (PLP)-dependent enzyme that includes the cytoplasmic SHMT1, and the mitochondrial SHMT2 isoforms (Florio et al., 2011; Ueland et al., 2015). The second pathway is the glycine cleavage system that catalyzes glycine cleavage up to formation of $\mathrm{CH}_{2}-\mathrm{H}_{4}$ PteGlu in mitochondria (Kikuchi et al., 2008; Ueland et al., 2015).

The rationale for the present hypothesis lies in the low affinity for binding of SHMT apoenzyme to cofactor. PLP was found to bind purified bovine liver SHMT1 with dissociation constant $\left(\mathrm{K}_{\mathrm{D}}\right)$ as high as $27 \mu \mathrm{M}$ (Jones and Priest, 1978), and it was reported to bind rabbit liver SHMT with a $K_{D}$ of $700 \mathrm{nM}$ (Schirch et al., 1973). Human recombinant SHMT1 bound to cofactor with a $\mathrm{K}_{\mathrm{D}}$ of $850 \mathrm{nM}$ in one study (Perry et al., 2007), and in another study human recombinant SHMT1 and SHMT2 bound to cofactor with $\mathrm{K}_{\mathrm{D}}$ of 250 and $440 \mathrm{nM}$, respectively (Giardina et al., 2015). By contrast, levels of naturally occurring PLP in human erythrocytes under basal conditions are as small as 30-100 nmol/l 100\% packed red cells (Zempleni and Kübler, 1994). Although mechanisms of intracellular cofactor supply to PLP-dependent enzymes are only partially known (Di Salvo et al., 2011), these features indicate that SHMT activity should be sensitive to PLP concentration changes.
We hypothesized that supplementation of cancer cells with high amounts of PLP would facilitate production of $\mathrm{CH}_{2}$ $\mathrm{H}_{4}$ PteGlu and modulate FUra through formation and stabilization of the ternary complex, resulting in augmentation of the cytotoxic effect. To test the hypothesis, experiments were conducted in three cancer cell line models in vitro to investigate for interactions between FUra, FA, and PLP on cell growth.

\section{Materials and Methods}

Cell Lines and Cytotoxicity Studies In Vitro. The human colorectal carcinoma cell lines HT29 and HCT116 and the murine L1210 lymphocytic leukemia were obtained from American Type Culture Collection (Manassas, VA). These cell lines were chosen for their sensitivity to the cytotoxic action of the fluoropyrimidines and for their use as models for preclinical experiments in vivo. Cells were thawed from mycoplasma-free frozen stocks and were controlled for contamination. The three cell lines were grown in customized Dulbecco's modified Eagle's cell culture medium without any B6 vitamer (Gibco; Life Technologies, Thermo Fisher Scientific. Courtaboeuf, France) supplemented with $10 \%$ fetal bovine serum and antibiotics $\left(50 \mu \mathrm{g} / \mathrm{ml}\right.$ streptomycin and $50 \mathrm{U} / \mathrm{ml}$ penicillin) at $37^{\circ} \mathrm{C}$ in an atmosphere with $5 \% \mathrm{CO}_{2}$. We analyzed HT29 cells growing in customized medium without vitamin B6 and did not observe any impact on growth after as much as five successive passages of 96-hour cultures. We also verified that neither FA nor PLP as single agents and in combination carry cytotoxic properties per se in the concentrations used in the present study.

Cells were exposed in 12-well cell plates to FUra in various concentrations under four conditions: either as a single agent (FUra); in combination with 6R,S-FA (FUra-FA); in combination with PLP (Sigma-Aldrich, Darmstadt, Germany) (FUra-PLP); and with both 6R, S-FA and PLP combined (FUra-FA-PLP). Cells were exposed to PLP at the single concentration of $160 \mu \mathrm{M}$, and to $\mathrm{FA}$ at $20 \mu \mathrm{M}$, a concentration reported to be required for maximum potentiation of the fluoropyrimidines in vitro (Ullman et al., 1978). Cells were harvested 72 hours from start of exposure. Cell viability was measured with the trypan blue dye exclusion test in Malassez chambers and by flow cytometry. For the latter method, living cells defined by light

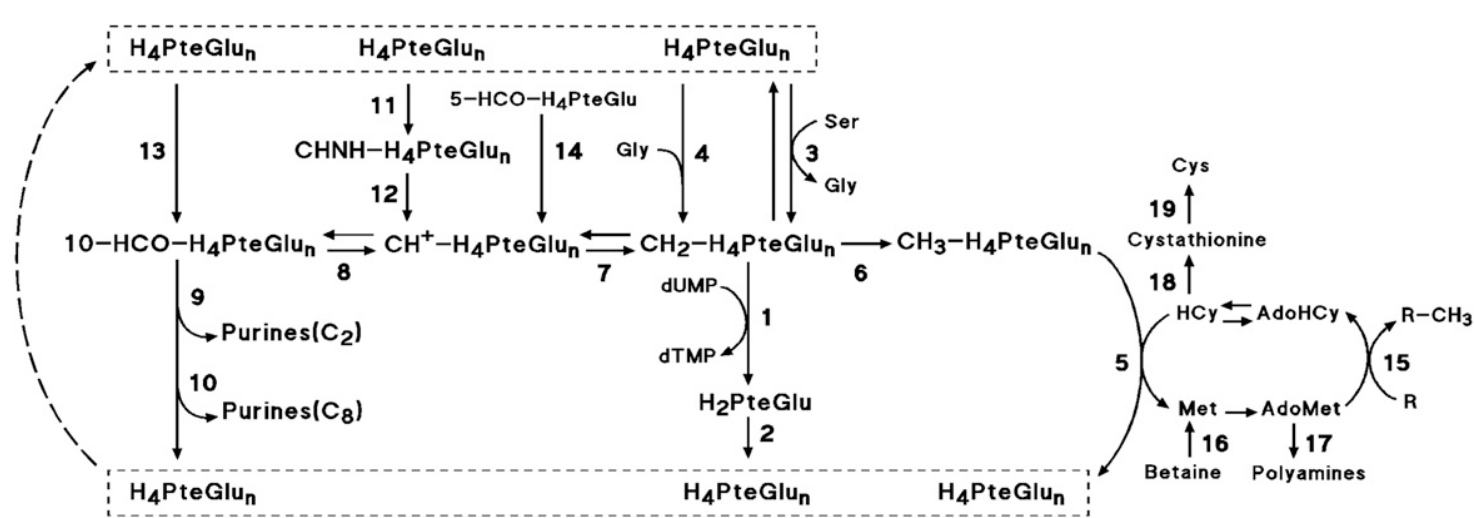

Fig. 1. Selected biochemical pathways of folates. $\mathrm{H}_{2}$ PteGlu: 7,8-dihydrofolate; $\mathrm{H}_{4}$ PteGlu: tetrahydrofolate; $\mathrm{CH}_{2}-\mathrm{H}_{4} \mathrm{PteGlu}$ 5,10-methylenetetrahydrofolate; $\mathrm{CH}_{3}-\mathrm{H}_{4}$ PteGlu: 5-methyltetrahydrofolate; $\mathrm{CH}^{+}-\mathrm{H}_{4}$ PteGlu: 5,10-methenyltetrahydrofolate; 10-HCO- $\mathrm{H}_{4} \mathrm{PteGlu}$ : 10 -formyltetrahydrofolate; CHNH-H${ }_{4}$ PteGlu: 5-formiminotetrahydrofolate; 5-HCO- ${ }_{4}$ PteGlu: [6S]-5-formyltetrahydrofolate (FA; leucovorin). 1) Thymidylate synthase; 2) dihydrofolate reductase; 3) PLP-dependent serine hydroxymethyltransferase (including the cytoplasmic SHMT1 and the mitochondrial SHMT2 isoforms); 4) glycine cleavage system (including the carrier $\mathrm{H}$ protein bound to the mitochondrial inner membrane, and the enzymes $\mathrm{P}$ protein, a PLPdependent glycine dehydrogenase, T protein, an amino methyltransferase, and L protein, a dihydro lipoamide dehydrogenase); 5) methionine synthase; 6) methylenetetrahydrofolate reductase; 7) methylenetetrahydrofolate dehydrogenase; 8) methenyltetrahydrofolate cyclohydrolase; 9) phosphoribosylglycinamide formyltransferase; 10) aminoimidazole carboxamide ribonucleotide formyltransferase; 11) formiminotransferase cyclodeaminase; 12) formiminotetrahydrofolate cyclodeaminase; 13 ) formate tetrahydrofolate ligase; 14 ) 5 -formyltetrahydrofolate cycloligase; 15) activated methyl transfer enzymes; 16) betaine-homocysteine methyltransferase; 17) adenosylmethionine decarboxylase; the PLP-dependent 18) cystathionine $\beta$-synthase, and 19) cystathionine $\gamma$-lyase. AdoHCy, S-adenosyl-L-homocysteine; AdoMet, S-adenosyl-L-methionine; HCy, L-homocysteine; Met, L-methionine. 
double scatter were counted in a BD Accuri C6 flow cytometer (BD Biosciences, Le-Pont-de-Claix, France). Experiments were done in duplicate. Control cells for each experimental condition were that grown in the absence of FUra, either with FA or PLP as single agents, with FA and PLP in combination, or with none of these.

Analysis of Drug Interaction on Cytotoxicity: Statistical Methods. Cell growth inhibition data obtained with FUra, FUra-FA, FUra-PLP, and FUra-FA-PLP in the three cancer cell lines were analyzed according to the mass-action law-based median-effect principle for concentration-effect analysis. The combination index (CI) proposed by Chou and Talalay (1984) was used for determination of synergism, additive effect, and antagonism. The median-effect equation correlates the dose (i.e., the concentration) of the drug and the effect produced in the form $\mathrm{f}_{\mathrm{a}} / \mathrm{f}_{\mathrm{u}}=\left(\mathrm{D} / \mathrm{D}_{\mathrm{m}}\right)^{\mathrm{m}}$, where $\mathrm{D}$ is the dose of drug; $D_{m}$ is the median-effect dose signifying potency (the $\left.\mathrm{IC}_{50}\right) ; \mathrm{f}_{\mathrm{a}}$ is the fraction of cells affected by the dose; $f_{u}$ is the fraction of cells unaffected $\left(f_{u}=1-f_{a}\right)$; and $m$ is a coefficient for shape of the dose-effect curve (sigmoidicity). The conformity of experimental data to the median-effect principle is represented by the linear correlation coefficient $r$ of the median-effect plot. The combination index equation $\mathrm{CI}=(\mathrm{D})_{1} /\left(\mathrm{D}_{\mathrm{x}}\right)_{1}+(\mathrm{D})_{2} /\left(\mathrm{D}_{\mathrm{x}}\right)_{2}$ was used for studies of cytotoxic interaction between drugs. The CI equation dictates that dose of drug $1(\mathrm{D})_{1}$ and dose of drug $2(\mathrm{D})_{2}$ in combination inhibit cell growth by $\mathrm{x} \%$. $(\mathrm{Dx})_{1}$ and $(\mathrm{Dx})_{2}$ are the doses of drug 1 and of drug 2 alone that also inhibit $\mathrm{x} \%$. $(\mathrm{Dx})_{1}$ and $(\mathrm{Dx})_{2}$ are calculated from the median-effect equation, where $\mathrm{D}$ is designated for $\mathrm{x} \%$ growth inhibition. Values for $\mathrm{CI}<1$, CI $=1$, and CI $>1$ indicate synergism, additive effect, and antagonism between drugs, respectively.

The experimental schema for studies of drug interaction included FUra-FA as drug 1, FUra-PLP as drug 2, and the combination (FUra-FA-PLP). Combination indices were calculated with the CI equation from the effect on cell growth produced by drugs FUra-FA and FUra-PLP used alone, and by the combination FUraFA-PLP at 1:1 constant concentration ratio assuming, for simplicity in data analysis, that the bio modulators (i.e., FA and PLP) affect FUra cytotoxicity through mutually exclusive mechanisms (i.e., that have similar modes of action). For representation of synergism, summation, and antagonism, the combination indices for FUra-FA-PLP were plotted as CI with respect to percentage of cells inhibited $\left(f_{a}\right)$.

Median-effect parameters, median-effect and dose-effect plots, combination indices, CI- $f_{\mathrm{a}}$ plots, and calculations of error were obtained with the CalcuSyn v2 Software (Biosoft, Cambridge, UK). Dose-effect S.E. was calculated assuming that $\mathrm{D}_{\mathrm{m}}$ has lognormal distribution. Estimated 1.96 S.D. for combination indices was calculated using a Monte-Carlo simulation (Belen'kii and Schinazi, 1994).

Statistical analysis of cytotoxicity was done by two-way Fisher analysis of variance (ANOVA) for cell effect in regard to factors defined as 1) concentration of FUra and 2) experimental condition (i.e., FUra, FUra-FA, FUra-PLP, and FUra-FA-PLP) in pooled data from the three cancer cell lines. Normal distribution of data was determined with the Kolmogorov-Smirnov normality test. The effect on cell growth $\left(f_{a}\right)$ between the four experimental conditions was tested according to the various concentrations of FUra. Concentration of FUra and experimental condition were tested for interaction. In absence of interaction found between factors (described below), oneway ANOVA defined by experimental condition was performed, followed by post hoc tests (Tukey) with multi-comparisons between experimental conditions two by two. Subsequent univariate analysis and post hoc tests were performed for each cell line separately. Statistical analysis was done with the $\mathrm{R}$ software, v3.2.3.

Intracellular Conversion of B6 Vitamers In Vivo. Vitamin B6 is the generic name that encompasses six interconvertible compounds (i.e., B6 vitamers), namely pyridoxine (PN); pyridoxamine (PM); pyridoxal (PL); (PL); and their respective $5^{\prime}$ phosphorylated forms, pyridoxine $5^{\prime}$-phosphate (PNP), pyridoxamine $5^{\prime}$-phosphate (PMP), and the cofactor PLP. Erythrocyte pharmacokinetics of B6 vitamers was studied in mice after parenteral PM in high doses to explore the physiologic limits of cells to synthesize and accumulate PLP in vivo in search for attaining intracellular levels of PLP in the range of $K_{D}$ values for binding of cofactor to apo SHMT or greater. We measured mouse erythrocyte levels of PMP, PL, and PLP resulting from conversion of parenteral PM. Female BALB/c mice aged 6 weeks, caged and fed under standard conditions, were given i.p. PM (SigmaAldrich) either at $150 \mathrm{mg} / \mathrm{kg}$ or at $450 \mathrm{mg} / \mathrm{kg}$ at time 0 only ( $t 0)$, or twice at time 0 and after 12 hours from start (i.e., at times $t 0$ and $t 12 \mathrm{~h}$ ). For each PM dose explored, groups of two mice each subjected to one injection of PM at $t 0$ were sacrificed and sampled after $1,3,6$, and 12 hours from start, and two animals that received two injections of PM were sampled 12 hours after the second injection (i.e., 24 hours after start of the experiment). Blood was collected in heparin. Measurements of $\mathrm{B} 6$ vitamers were done by high-performance liquid chromatography (Bisp et al., 2002).

\section{Results}

Cytotoxicity of FUra Was Increased by FA and PLP. Dose-effect data (Fig. 2), including $\mathrm{IC}_{50}$ changes in each experimental condition (Table 1), indicate that, in the three cell lines studied, FUra cytotoxicity was enhanced by FA, and by PLP, with the strongest effect resulting from the combination of FUra with both PLP and FA. IC 50 values obtained in each of the three cell lines with FUra combined with each bio modulator individually were of same magnitude, approximately half of that with FUra as a single agent. $\mathrm{IC}_{50}$ values of FUra in combination with PLP and FA in tandem were approximately eightfold smaller than that of FUra as a single agent in HT29 and L1210 cells, and were approximately fourfold smaller than that with FUra as a single agent in HCT116 cells.
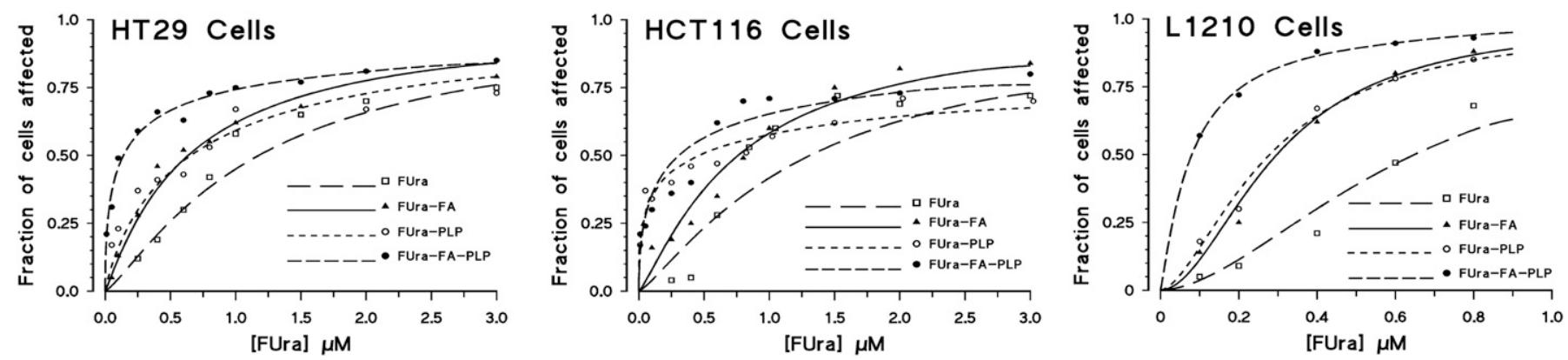

Fig. 2. Dose-effect plots of FUra as a single agent (FUra), FUra with FA (FUra-FA), FUra with PLP (FUra-PLP), and FUra with both FA and PLP combined (FUra-FA-PLP) in the human colorectal carcinoma cell lines HT29 and HCT116, and in the murine lymphocytic leukemia L1210. Symbols represent experimental points obtained for each condition. Plots were obtained with the CalcuSyn v2 software (Biosoft). 
TABLE 1

Median-effect parameters and combination indices of FUra as a single agent and in combination with FA and PLP in HT29, HCT116, and L1210 cancer cell lines

\begin{tabular}{|c|c|c|c|c|c|c|c|}
\hline \multirow{2}{*}{ Cell Line ${ }^{a}$} & \multirow{2}{*}{ Drug $^{b}$} & \multicolumn{3}{|r|}{ Parameter $^{c}$} & \multicolumn{3}{|c|}{ Combination Index Value (1.96 S.D.) at Fractional Effect: } \\
\hline & & $\mathrm{m}$ & $r$ & $\mathrm{D}_{\mathrm{m}}\left(\mathrm{IC}_{50}\right)$ and $95 \% \mathrm{CI}$ in $\mu \mathrm{M}$ & $\mathrm{IC}_{25}$ & $\mathrm{IC}_{50}$ & $\mathrm{IC}_{75}$ \\
\hline \multirow[t]{4}{*}{ HT29 } & FUra & 1.236 & 0.949 & $1.18(0.76-1.82)$ & - & - & - \\
\hline & FUra-FA & 1.082 & 0.994 & $0.64(0.55-0.74)$ & - & - & - \\
\hline & FUra-PLP & 0.883 & 0.960 & $0.66(0.44-0.99)$ & - & - & - \\
\hline & FUra-FA-PLP & 0.539 & 0.989 & $0.14(0.10-0.19)$ & $0.18(0.03)$ & $0.43(0.06)$ & $1.08(0.16)$ \\
\hline \multirow[t]{4}{*}{ HCT116 } & FUra & 1.23 & 0.921 & $1.31(0.74-2.32)$ & - & - & - \\
\hline & FUra-FA & 1.21 & 0.965 & $0.76(0.53-1.10)$ & - & - & - \\
\hline & FUra-PLP & 0.40 & 0.965 & $0.46(0.30-0.71)$ & - & - & - \\
\hline & FUra-FA-PLP & 0.53 & 0.941 & $0.31(0.16-0.58)$ & $1.43(0.6)$ & $1.07(0.24)$ & $1.61(0.56)$ \\
\hline \multirow[t]{4}{*}{ L1210 } & FUra & 1.75 & 0.969 & $0.65(0.40-1.06)$ & - & - & - \\
\hline & FUra-FA & 1.89 & 0.990 & $0.30(0.20-0.44)$ & - & - & - \\
\hline & FUra-PLP & 1.635 & 0.991 & $0.28(0.19-0.41)$ & - & - & - \\
\hline & FUra-FA-PLP & 1.15 & 0.995 & $0.08(0.05-0.11)$ & - & $0.56(0.06)$ & $0.77(0.06)$ \\
\hline
\end{tabular}

\footnotetext{
${ }^{a}$ Cancer cells were the human colorectal carcinoma cell lines HT29 and HCT116 and the L1210 murine lymphocytic leukemia.

${ }^{b}$ Cells were grown in customized Dulbecco's modified Eagle's cell culture medium without any B6 vitamer supplemented with $10 \%$ fetal bovine serum and were exposed for 72 hours to FUra as a single agent, FUra and FA (20 $\mu \mathrm{M})$, FUra and PLP (160 $\mu \mathrm{M})$, and FUra with both FA (20 $\mu \mathrm{M})$ and PLP $(160 \mu \mathrm{M})$.

${ }^{c}$ Median-effect parameters are the median-effect dose $\left(D_{m}\right)$ and a coefficient $(m)$ for shape (sigmoidicity) of the dose-effect curve. The linear correlation coefficient of the median-effect plot $(r)$ represents conformity of experimental data to the median-effect principle. Median-effect parameters, combination indices, and calculations of error were obtained with the CalcuSyn v2 Software (Biosoft).
}

Two-way Fisher ANOVA identified a significant difference in cell effect between the four experimental conditions $(P=$ 3.73.10 11 ). The test also found that the concentration of FUra affects cell growth significantly $\left(P<2.2 .10^{-16}\right)$. Lastly, no significant interaction was found between the two factors tested (i.e., concentration of FUra and experimental condition) throughout the entire FUra concentration range from 0.01 to $3 \mu \mathrm{M}(P=0.2929)$. Post hoc tests (Tukey) comparing experimental conditions two by two in pooled data from the three cancer cell lines found a statistically significant difference $(P<0.001)$ in comparisons of FUra-FA-PLP versus FUra. Tests did not reach significant differences in other comparisons between experimental conditions. Univariate Fisher ANOVA and Tukey post hoc tests performed in each cancer cell line separately found significant differences in cell effect in comparisons of FUra-FA-PLP versus FUra in HT29 $(P=$ $0.002)$, HCT116 $(P=0.05)$, and L1210 $(P<0.001)$ cancer cells. As for tests performed with pooled data, no significant differences were found in other comparisons two by two between experimental conditions.

Combination indices for FUra-FA-PLP were of synergistic significance $(<1)$ for $\mathrm{f}_{\mathrm{a}}$ up to 0.70 in HT2 9 cells, and up to 0.80 in L1210 cells (Fig. 3; Table 1). Below these fractional effect limits, CI simulations followed a continuous trend for synergy of the effect of combined FA and PLP in tandem on FUra cytotoxicity. For HCT116 cells, CI values were scattered. Only a small number of experimental values was of synergistic significance, whereas the majority was above 1 . In HCT116 cells, CI simulations followed a trend for summation of the effect of FA and PLP combined on FUra cytotoxicity within a fractional effect range of approximately $0.40-0.60$, with values above 1 outside these limits.

Parenteral Pyridoxamine Resulted in High Erythrocyte PLP Levels. Basal PLP concentration in erythrocytes was $31 \pm 7 \mathrm{nmol} / \mathrm{l} 100 \%$ packed red cells (Fig. 4). Parenteral PM resulted in rapid increase of intracellular PLP, attaining a maximum concentration between 1 and 3 hours after injection. Mean peak erythrocyte PLP concentrations were $382 \mathrm{nmol} / \mathrm{l} 100 \%$ packed red cells in mice that received PM at $150 \mathrm{mg} / \mathrm{kg}$, and $2326 \mathrm{nmol} / \mathrm{l} 100 \%$ packed red cells in mice that received PM at $450 \mathrm{mg} / \mathrm{kg}$. PLP levels rapidly decreased after the third hour, approaching baseline concentrations by 12 hours after injection. This observation was similar in animals that received two injections of PM (i.e., at times $t 0$ and $t 12 \mathrm{~h}$ ), indicating that cellular clearance of newly synthesized PLP is rapid and that cofactor is not appreciably accumulated in cells when injections are repeated at 12-hour interval. Metabolic conversion of PM also resulted in production of large amounts of PL and PMP. No signs of acute toxicity were observed during the time of the study in mice receiving either one or two injections of PM at any of the two doses administered.

\section{Discussion}

Concentration-effect data studied according to the median-effect principle indicate enhancement of the cytotoxic action of FUra by high-concentration FA. Similarly, data suggest increase of FUra cytotoxicity by PLP. The strongest growth-inhibiting effect resulted from the combination of FUra, FA, and PLP in the three cancer cell lines studied. Statistical analysis of cell effect data confirms that the combination of FUra, FA, and pyridoxal 5 '-phosphate in tandem produces significantly greater cytotoxicity than FUra as a single agent, which supports enhancement of the action of FUra by the two modulators in combination. In contrast with the concentration-effect data obtained according to the median-effect principle, statistical analysis could not significantly differentiate FUra combined with one single modulator (i.e., FA or PLP) from FUra as a single agent. Combination indices and CI- $f_{a}$ plots indicate that FA and PLP interact synergistically on FUra cytotoxicity in HT29 and L1210 cells within a large cell effect range. In HCT116 cells, the two bio modulators produce summation of their effects on FUra cytotoxicity over a narrow fractional effect range.

Effects of B6 vitamers on FUra cytotoxicity have not been reported previously. The present data fit with the assumption of cellular changes produced by the bio modulators that 

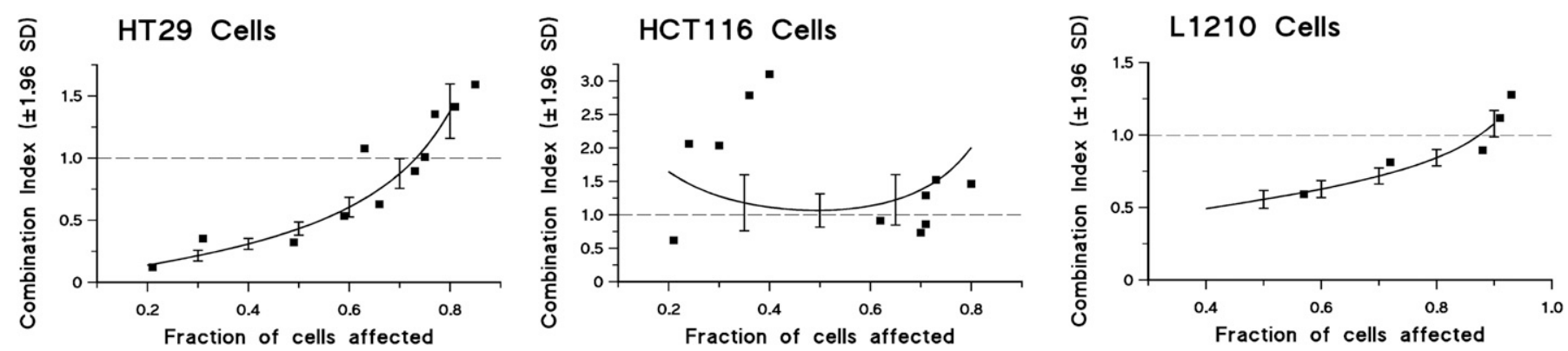

Fig. 3. CI with respect to $f_{a}$ plots in the human colorectal carcinoma cell lines HT29 and HCT116, and in the murine lymphocytic leukemia L1210. Solid squares represent experimental values of CI calculated for the combination of FUra, FA, and pyridoxal 5'-phosphate in tandem producing a given effect. Continuous line represents simulation of the $\mathrm{CI}$ with respect to $\mathrm{f}_{\mathrm{a}}$, and vertical bars represent $\pm 1.96 \mathrm{~S}$.D. Values for CI $<1$, CI $=1$, and CI $>1$ indicate synergism, additive effect, and antagonism between drugs, respectively. The experimental schema is detailed under Materials and Methods. Plots and calculations of error were obtained with the CalcuSyn v2 software (Biosoft).

contribute synergistically for improvement of FUra cytotoxic effect in two of the three cancer cell lines studied. From our results and the rationale presented, we hypothesize that FA in combination with vitamin $\mathrm{B} 6$ facilitates expansion of $\mathrm{CH}_{2}$ $\mathrm{H}_{4}$ PteGlu pool in cancer cells leading, in the presence of FdUMP, to increased ternary complex formation and stabilization with concomitant inhibition of the TS. However, the mechanisms of the interaction remain to be determined.

Evidence for folate-mediated one-carbon metabolism changes through SHMT related to vitamin B6 availability was previously reported. One study has shown that vitamin B6 deficiency in rat reduced PLP levels and SHMT activity in liver, together with decreased remethylation of homocysteine in methionine with serine-derived methyl groups, i.e., generated through SHMT-catalyzed synthesis of $\mathrm{CH}_{2}-\mathrm{H}_{4}$ PteGlu (Martínez et al., 2000). In another study, investigators found that vitamin B6 restriction decreased cellular PLP levels and SHMT activity in MCF-7 human mammary carcinoma cells in vitro and was accompanied by decrease in levels of S-adenosyl-methionine. Addition of PLP increased SHMT activity up to 4.2-fold in extracts of MCF-7 cells grown in vitamin B6-deficient medium, which reflects the fraction of the SHMT pool that was present as inactive apoenzyme (Perry et al., 2007). These findings strongly support the present hypothesis of expansion of methylenetetrahydrofolate pools due to increase in SHMT activity by supplying PLP in cancer cells.

The pharmacokinetic study presented in this work demonstrates that erythrocytes rapidly metabolize pyridoxamine in vivo, resulting in high intracellular levels of PLP. Erythrocyte PLP attains levels close to or greater than most $K_{D}$ values reported for binding of cofactor to SHMT, which suggests that
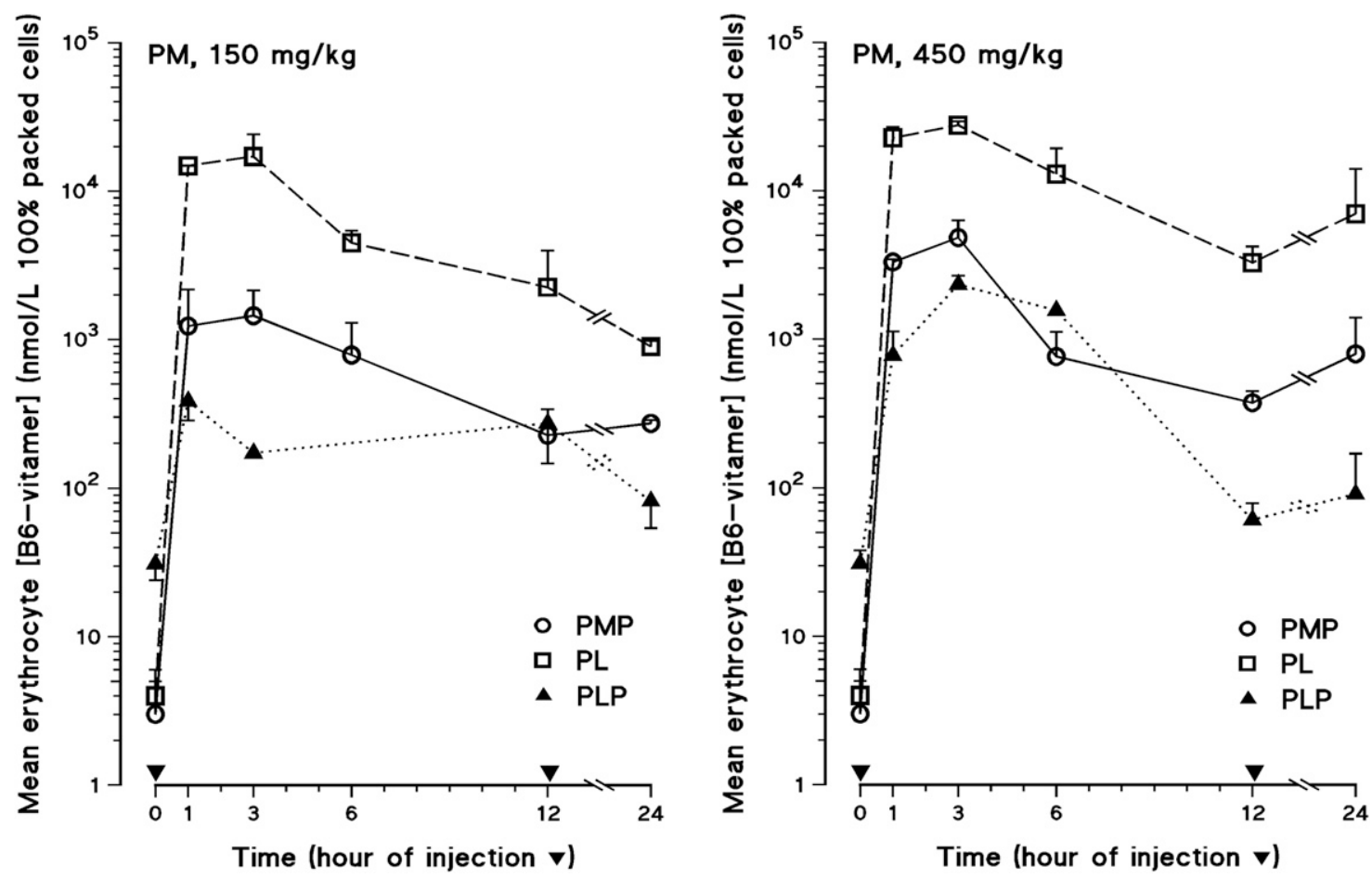

Fig. 4. Mouse erythrocyte levels of PMP, PL, and PLP after i.p. PM. BALB/c mice were given PM at $150 \mathrm{mg} / \mathrm{kg}$ or at $450 \mathrm{mg} / \mathrm{kg}$ at time 0 only, or twice at time 0 and after 12 hours from start. For each PM dose explored, measurements were done after 1, 3, 6, 12, and 24 hours from start of the experiment. Vertical bars indicate S.E. 
activity of the enzyme may be increased by intracellular PLP expansion within cancer cells in vivo. However, decline of intracellular PLP to basal levels occurs in less than 12 hours from injection. The mechanisms underlying the absence of PLP accumulation within cells have not been elucidated. Our findings in mice are in accordance with that reported on intracellular pharmacokinetics of PMP, PL, and PLP after parenteral administration of $\mathrm{PN}$ in humans (Zempleni and Kübler, 1994; Ueland et al., 2015).

Effective uptake of PLP by erythrocytes in vitro was previously demonstrated (Suzue and Tachibana, 1970; Maeda et al., 1976). However, intracellular cofactor levels in cancer cells under exposure to high concentration PLP have not yet been determined. Correlating levels of PLP required for enhancement of FUra-dependent cytotoxicity in cancer cells in vitro to that attained in erythrocytes after parenteral pyridoxamine may help finding schemas for preclinical studies.

Further exploration of the bio modulation of fluoropyrimidines by FA and vitamin B6 in tandem should be considered for improvement of the cytotoxic effect in cancer cells.

\section{Acknowledgments}

We thank Philippe Machover for statistical support.

\section{Authorship Contributions}

Participated in research design: Machover, Goldschmidt, GastonMathé.

Conducted experiments: Machover, Mollicone, Haghighi-Rad, Dairou.

Contributed new reagents or analytic tools: Machover, Mollicone, Haghighi-Rad, Gaston-Mathé, Dairou.

Performed data analysis: Machover, Goldschmidt, Desterke,

Dairou.

Wrote or contributed to the writing of the manuscript: Machover, Goldschmidt, Desterke, Saffroy, Boucheix.

\section{References}

Belen'kii MS and Schinazi RF (1994) Multiple drug effect analysis with confidence interval. Antiviral Res 25:1-11.

Bisp MR, Bor MV, Heinsvig EM, Kall MA, and Nexø E (2002) Determination of vitamin B6 vitamers and pyridoxic acid in plasma: development and evaluation of a high-performance liquid chromatographic assay. Anal Biochem 305:82-89.

Boarman DM and Allegra CJ (1992) Intracellular metabolism of 5-formyl tetrahydrofolate in human breast and colon cell lines. Cancer Res 52:36-44.

Chou T-C and Talalay P (1984) Quantitative analysis of dose-effect relationships: the combined effects of multiple drugs or enzyme inhibitors. Adv Enzyme Regul 22: 27-55.

Danenberg PV and Danenberg KD (1978) Effect of 5,10-methylenetetrahydrofolate on the dissociation of 5-fluoro-2'-deoxyuridylate from thymidylate synthetase: evidence for an ordered mechanism. Biochemistry 17:4018-4024.

di Salvo ML, Contestabile R, and Safo MK (2011) Vitamin B(6) salvage enzymes: mechanism, structure and regulation. Biochim Biophys Acta 1814:1597-1608.

Florio R, di Salvo ML, Vivoli M, and Contestabile R (2011) Serine hydroxymethyltransferase: a model enzyme for mechanistic, structural, and evolutionary studies. Biochim Biophys Acta 1814:1489-1496.

Giardina G, Brunotti P, Fiascarelli A, Cicalini A, Costa MGS, Buckle AM, di Salvo ML, Giorgi A, Marani M, Paone A, et al. (2015) How pyridoxal 5'-phosphate differentially regulates human cytosolic and mitochondrial serine hydroxymethyltransferase oligomeric state. FEBS J 282:1225-1241.

Houghton JA, Williams LG, Cheshire PJ, Wainer IW, Jadaud P, and Houghton PJ (1990) Influence of dose of [6RS]leucovorin on reduced folate pools and 5-fluorouracil-mediated thymidylate synthase inhibition in human colon adenocarcinoma xenografts. Cancer Res 50:3940-3946.

Jones CW, III and Priest DG (1978) Interaction of pyridoxal 5-phosphate with aposerine hydroxymethyltransferase. Biochim Biophys Acta 526:369-374.

Kikuchi G, Motokawa Y, Yoshida T, and Hiraga K (2008) Glycine cleavage system reaction mechanism, physiological significance, and hyperglycinemia. Proc Jpn Acad Ser B Phys Biol Sci 84:246-263.

Lockshin A and Danenberg PV (1981) Biochemical factors affecting the tightness of 5 -fluorodeoxyuridylate binding to human thymidylate synthetase. Biochem Pharmacol 30:247-257.

Machover D, Grison X, Goldschmidt E, Zittoun J, Lotz J-P, Metzger G, Richaud J, Hannoun L, Marquet J, Guillot T, et al. (1992) Fluorouracil combined with the pure (6S)-stereoisomer of folinic acid in high doses for treatment of patients with advanced colorectal carcinoma: a phase I-II study. J Natl Cancer Inst 84: 321-327.

Machover D, Schwarzenberg L, Goldschmidt E, Tourani JM, Michalski B, Hayat M, Dorval T, Misset JL, Jasmin C, Maral R, et al. (1982) Treatment of advanced colorectal and gastric adenocarcinomas with 5-FU combined with high-dose folinic acid: a pilot study. Cancer Treat Rep 66:1803-1807.

Machover D, Zittoun J, Broët P, Metzger G, Orrico M, Goldschmidt E, Schilf A Tonetti C, Tan Y, Delmas-Marsalet B, et al. (2001) Cytotoxic synergism of methioninase in combination with 5-fluorouracil and folinic acid. Biochem Pharmacol 61:867-876.

Maeda N, Takahashi K, Aono K, and Shiga T (1976) Effect of pyridoxal 5'-phosphate on the oxygen affinity of human erythrocytes. Br J Haematol 34:501-509.

Martínez M, Cuskelly GJ, Williamson J, Toth JP, and Gregory JF, III (2000) Vitamin B-6 deficiency in rats reduces hepatic serine hydroxymethyltransferase and cystathionine $\beta$-synthase activities and rates of in vivo protein turnover, homocysteine remethylation and transsulfuration. $J$ Nutr 130:1115-1123.

Nixon PF, Slutsky G, Nahas A, and Bertino JR (1973) The turnover of folate coenzymes in murine lymphoma cells. J Biol Chem 248:5932-5936.

Perry C, Yu S, Chen J, Matharu KS, and Stover PJ (2007) Effect of vitamin B6 availability on serine hydroxymethyltransferase in MCF-7 cells. Arch Biochem Biophys 462:21-27.

Piedbois P, Buyse M, Rustum Y, Machover D, Erlichman C, Carlson RW, Valone F Labianca R, Doroshow JH, and Petrelli N; Advanced Colorectal Cancer MetaAnalysis Project (1992) Modulation of fluorouracil by leucovorin in patients with advanced colorectal cancer: evidence in terms of response rate. $J$ Clin Oncol 10: 896-903.

Priest DG, Schmitz JC, and Bunni MA (1993) Folate metabolites as modulators of antitumor drug activity, in Chemistry and Biology of Pteridines and Folates (Ayling JE ed) pp 693-697, Plenum Press, New York.

Romanini A, Lin JT, Niedzwiecki D, Bunni M, Priest DG, and Bertino JR (1991) Role of folylpolyglutamates in biochemical modulation of fluoropyrimidines by leucovorin. Cancer Res 51:789-793.

Santi DV, McHenry CS, and Sommer H (1974) Mechanism of interaction of thymidylate synthetase with 5-fluorodeoxyuridylate. Biochemistry 13:471-481.

Schirch LV, Edmiston M, and Chen MS (1973) Serine transhydroxymethylase: subunit structure and the involvement of sulfhydryl groups in the activity of the enzyme. J Biol Chem 248:6456-6461.

Suzue R and Tachibana M (1970) The uptake of pyridoxal phosphate by human red blood cells. J Vitaminol (Kyoto) 16:164-171.

Ueland PM, Ulvik A, Rios-Ávila L, Midttun Ø, and Gregory JF (2015) Direct and functional biomarkers of vitamin B6 status. Annu Rev Nutr 35:33-70.

Ullman B, Lee M, Martin DW, Jr, and Santi DV (1978) Cytotoxicity of 5-fluoro-2'deoxyuridine: requirement for reduced folate cofactors and antagonism by methotrexate. Proc Natl Acad Sci USA 75:980-983.

Voeller DM and Allegra CJ (1994) Intracellular metabolism of 5-methyltetrahydrofolate and 5-formyltetrahydrofolate in a human breast-cancer cell line. Cancer Chemother Pharmacol 34:491-496.

Wright JE, Dreyfuss A, el-Magharbel I, Trites D, Jones SM, Holden SA, Rosowsky A and Frei E, III (1989) Selective expansion of 5,10-methylenetetrahydrofolate pools and modulation of 5 -fluorouracil antitumor activity by leucovorin in vivo. Cancer Res 49:2592-2596.

Zempleni J and Kübler W (1994) The utilization of intravenously infused pyridoxine in humans. Clin Chim Acta 229:27-36.

Zhang Z-G and Rustum YM (1991) Effects of diastereoisomers of 5 -formyltetrahydrofolate on cellular growth, sensitivity to 5 -fluoro-2'-deoxyuridine, and methylenetetrahydrofolate polyglutamate levels in HCT-8 cells. Cancer Res 51:3476-3481.

Address correspondence to: Dr. David Machover, Department of Medical Oncology, Hospital Paul-Brousse, 12 Avenue Paul-Vaillant-Couturier, 94800 Villejuif, France. E-mail: david.machover1@orange.fr 